\title{
A vulnerabilidade das "cidades da cana" no Triângulo Mineiro, MG, Brasil: efeitos territoriais do encerramento das atividades de usinas sucroenergéticas
}

\author{
The Vulnerability of the "sugarcane cities" in the Triângulo \\ Mineiro, MG, Brazil: territorial effects of the closure of \\ sugarcane industries
}

\section{La Vulnerabilidad de las "ciudades de la caña" en el Triângulo Mineiro, MG, Brasil: efectos territoriales de cierre de las actividades de industrias sucroenergéticas}

\author{
Mirlei Fachini Vicente Pereira \\ http:/ / orcid.org/0000-0002-1094-8829 \\ mirlei@ufu.br \\ Universidade Federal de Uberlândia, UFU, Uberlândia, MG \\ Ruhan Rodys Beiler \\ http:/ / orcid.org/0000-0003-0409-9936 \\ ruhanb@live.com \\ Universidade Estadual Paulista, UNESP, Rio Claro, SP
}

\begin{abstract}
Resumo: O texto avalia situações de vulnerabilidade territorial a partir do processo de especialização produtiva no setor sucroenergético em dois municípios localizados no Triângulo Mineiro, porção oeste do estado de Minas Gerais. Com significativa área destinada ao cultivo da cana e expressiva dependência dos empregos industriais e agrícolas gerados no setor, o encerramento das atividades de duas usinas sucroenergéticas implicou em novas condições aos municípios, produzindo consequências territoriais drásticas que envolvem a economia urbana e o cotidiano local.
\end{abstract}

Palavras-chave: Especialização produtiva, Uso do Território, Setor Sucroenergético.

Abstract: This paper evaluates situations of territorial vulnerability from the productive specialization process in the sugarcane industry in two municipalities located in the Triângulo Mineiro, Western Minas Gerais State. The significant area set apart to sugarcane planting carried out an expressive dependence on the industrial and agricultural jobs and the two sugarcane industries closure involved new conditions for municipalities. It was observed drastic territorial consequences involving the urban economy and local daily life.

Keywords: Productive specialization, Use of Territory, Sugarcane sector. 
Resumen: El artículo analiza situaciones de vulnerabilidad territorial a partir del proceso de especialización productiva en el sector sucroenergético, en dos municipios ubicados en el Triángulo Mineiro, porción oeste del estado de Minas Gerais. Con una significativa área destinada al cultivo de la caña y expresiva dependencia de los empleos industriales y agrícolas generados en el sector, el cierre de las actividades de dos industrias sucroenergéticas implicó en nuevas condiciones a los municipios, produciendo consecuencias territoriales drásticas que envuelven la economía urbana y el cotidiano local.

Palabras clave: Especialización productiva, Uso del Territorio, Sector Sucroenergético.

\section{INTRODUÇÃO}

De que modo a vulnerabilidade, atributo comumente destinado a grupos sociais ou indivíduos, pode alcançar uma expressão geográfica ou territorial? Em outras palavras, como o território e os lugares podem tornar-se vulneráveis em virtude das funções ou configurações espaciais que acolhem? É partindo de tais questões que o presente texto visa contribuir para a elucidação de processos que, no Brasil atual, são indicativos da produção de situações geográficas (Silveira, 1999) que revelam sintomas próprios dos mecanismos de especialização territorial que, se por um lado conferem crescimento econômico e algum dinamismo próprio do mercado, também produzem ou aprofundam situações de dependência capazes de tornar a população e os lugares expostos a vulnerabilidades extremas.

Isto ocorre em muitos dos municípios especializados nas atividades sucroenergéticas (cultivo de cana-de-açúcar e produção de derivados) que, com economias e trabalho muito dependentes do setor, tornam-se vulneráveis às lógicas de mercado ou à política de grupos econômicos hegemônicos. Este caráter de vulnerabilidade territorial se torna evidente nas situações de encerramento das atividades industriais.

No Triângulo Mineiro, porção oeste do estado de Minas Gerais, dois casos emblemáticos podem ser constatados nos municípios de Canápolis e Capinópolis, alvos principais de nossa avaliação. Assim, avaliamos as condições de vulnerabilidade territorial produzidas pelo setor nestes municípios, quando duas unidades agroindustriais pertencentes ao Grupo João Lyra encerraram as suas atividades no ano de 2013. A partir de análise conceitual e empírica, empreendida através de leituras e levantamentos de campo (entre os anos de 2015 e 2016), o trabalho avalia como o território alcançou condições de especialização, a partir do cultivo e processamento da cana, e como tais condições implicaram em vulnerabilidade e suas consequências, quando as usinas encerraram as atividades, bem como avalia as proposições dos municípios para a superação dos problemas locais, ainda que implicando em nova situação de subordinação.

\section{O setor sucroenergético no Brasil e no Triângulo Mineiro}

O território brasileiro conheceu, nas primeiras décadas do século atual, significativa expansão das atividades sucroenergéticas sintetizadas na produção agrícola de cana-de-açúcar e da agroindústria produtora de derivados (etanol, açúcares e energia elétrica). Tal 
processo resultou de uma nova vaga de modernização da produção agrícola e industrial, inclusive com o ingresso de novos agentes externos que reformulam por completo as atividades produtivas do tradicional setor no país.

Um conjunto de fatores externos e internos implicaram em substantivas transformações técnicas e territoriais do setor. Em linhas gerais, os fatores externos resultaram, sobretudo, do aumento da demanda mundial por commodities agrícolas na virada do milênio, no chamado boom das commodities (Delgado, 2012), o que, dentre outros aspectos, permitiu a elevação do preço do açúcar no mercado externo e a valorização do etanol como combustível alternativo à gasolina, conforme compromissos assumidos por vários países no Protocolo de Quioto, em 1997.

Os fatores internos que garantiram a expansão do setor sucroenergético resultaram, especialmente, do advento dos veículos flexfuel (bicombustível) a partir de 2003, que atualmente representam a maior parte da frota nacional, ampliando consideravelmente o mercado interno para o etanol combustível (Camelini \& Castillo, 2012), bem como dos anseios do Brasil em tornar-se um dos maiores exportadores de etanol, projeto este de certo modo frustrado com a emergência da crise financeira mundial de 2008 (Bernardes, 2013). Também como desdobramento da crise financeira internacional, um conjunto significativo de usinas encontra-se, desde então, com dificuldades financeiras, ocasionando falências e endividamento, o que ocasionou o encerramento das atividades em alguns municípios.

Em que pese tal situação, as condições externas e internas permitiram expansão considerável das atividades sucroenergéticas no Brasil, onde a área destinada à produção de cana-de-açúcar dobrou entre 2000 e 2015 (alcançando 10,1 milhões de hectares em 2015), conhecendo pequena queda nos últimos anos - foram 9,6 milhões de hectares ocupados com cana no Brasil em 2019, resultando em 667,5 milhões de toneladas produzidas de cana-de-açúcar (Instituto Brasileiro de Geografia e Estatística [IBGE], 2020).

Esta expansão em quantidade e em área foi acompanhada de significativa modernização agrícola, com crescente produtividade amparada em modernos pacotes tecnológicos que incluem desde aspectos da biotecnologia até o emprego de maquinários agrícolas e expressiva modernização industrial. Usinas de última geração otimizam a produção e em grande parte também se voltam à geração de energia elétrica pela utilização da biomassa. Tal situação de expansão implicou em reforço dos nexos de dependência e ampliação da inserção subordinada do país à economia global, perpetuando a condição do Brasil como produtor de commodities agrícolas (Pereira, 2010), e a afirmação, no território, daquilo que Svampa (2013) denominou como 'consenso de commodities'.

O processo de expansão do setor sucroenergético foi significativamente amparado por financiamentos públicos, especialmente via BNDES (Silva, 2017), inclusive a agentes estrangeiros que, sem tradição no setor sucroenergético, visualizam na exploração da atividade novas possibilidades de lucro na "cultura flexível" da cana (Borras Junior, Franco, Isakson, Levidow, \& Vervest, 2016), em vista da possibilidade de diferentes commodities resultantes do cultivo, como açúcar, etanol e energia elétrica.

Um conjunto expressivo de áreas localizadas no domínio do Cerrado, no Sudeste e Centro-Oeste (Castillo, 2015), conheceu expansão significativa dos cultivos e a inserção de 
novas unidades agroindustriais sucroenergéticas. No caso da mesorregião Triângulo Mineiro/ Alto Paranaíba, segundo IBGE (2020), esta é hoje responsável pela maior parte da produção mineira de cana e derivados, com mais de $70 \%$ da cana colhida e processada (Figs. 1 e 2).

Figura 1. Evolução da área plantada com cana-de-açúcar e da produção no Triângulo Mineiro/ Alto Paranaíba (1995-2015).

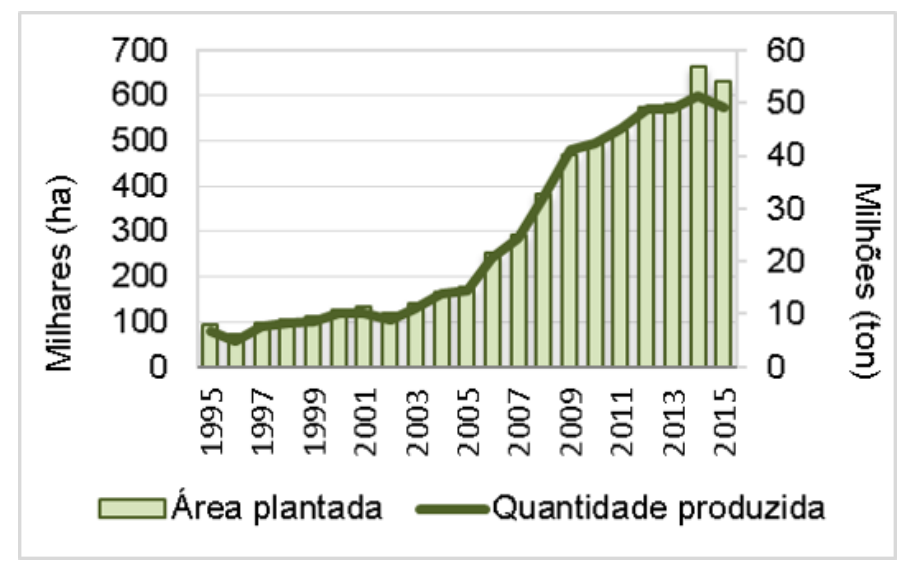

Fonte: IBGE-PAM, 2020.

Figura 2. Triângulo Mineiro/ Alto Paranaíba - Municípios avaliados e produção regional de cana-deaçúcar em toneladas (2015).

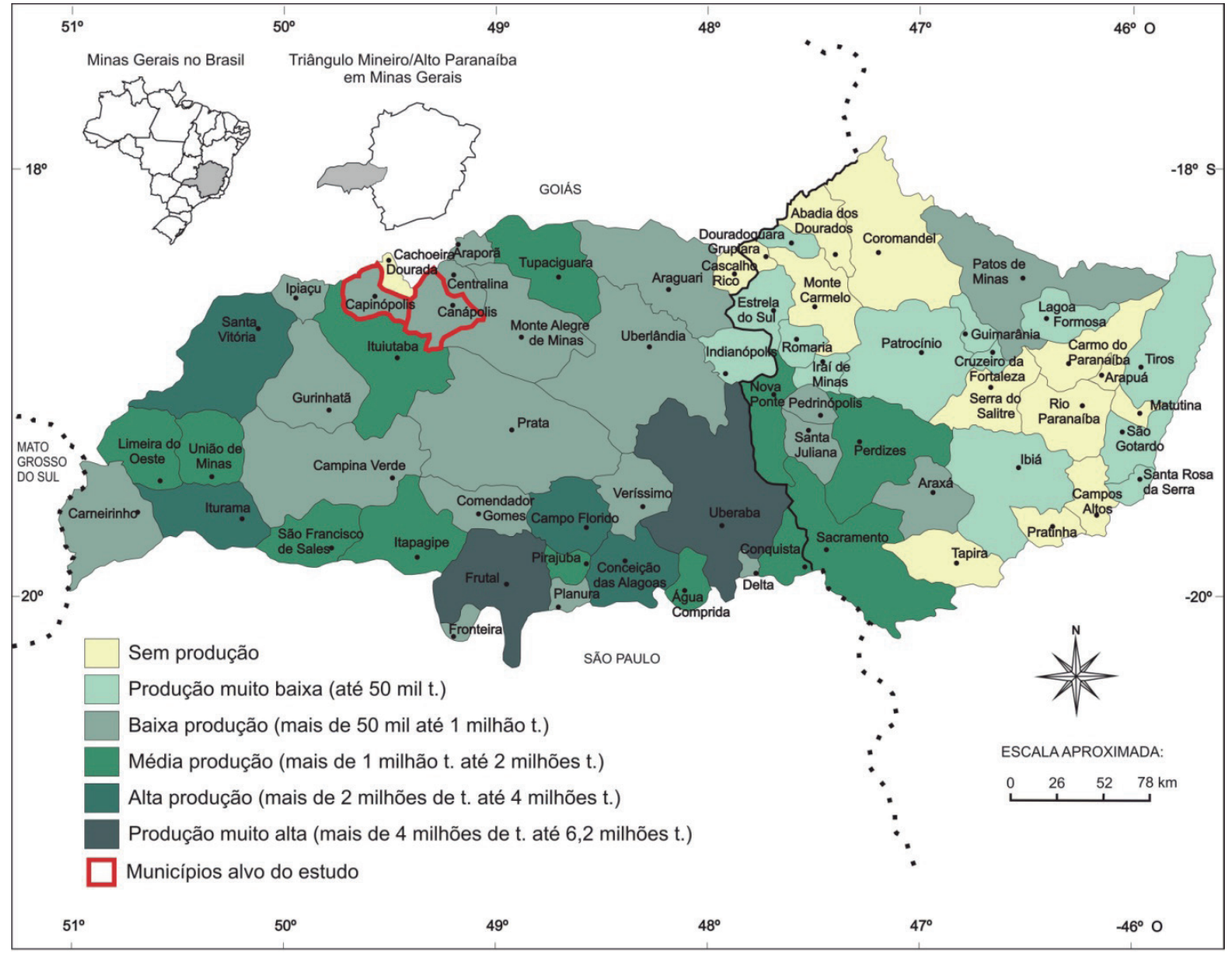

Fonte: IBGE-PAM, 2020. 
A partir de 2003, quando os fatores internos e externos já apontados permitiram a expansão significativa da produção sucroenergética no país, a cana-de-açúcar é a cultura que conhece maior expansão na mesorregião Triângulo Mineiro/Alto Paranaíba, aumentando em mais de três vezes a área ocupada (mais de 630 mil hectares em 2015) (Fig. 3), enquanto cultivos tradicionais diminuem ou permanecem estagnados (IBGE-PAM, 2020). Em que pese a substituição de algumas áreas voltadas a outros cultivos como soja e milho, a reconversão para o plantio da cana-de-açúcar ocorre fundamentalmente em áreas antes destinadas à pastagem e em alguns casos também pela substituição da vegetação nativa de Cerrado, como pudermos levantar em trabalhos de campo.

Figura 3. Evolução da área ocupada por culturas temporárias na mesorregião Triângulo Mineiro/Alto Paranaíba (hectares).

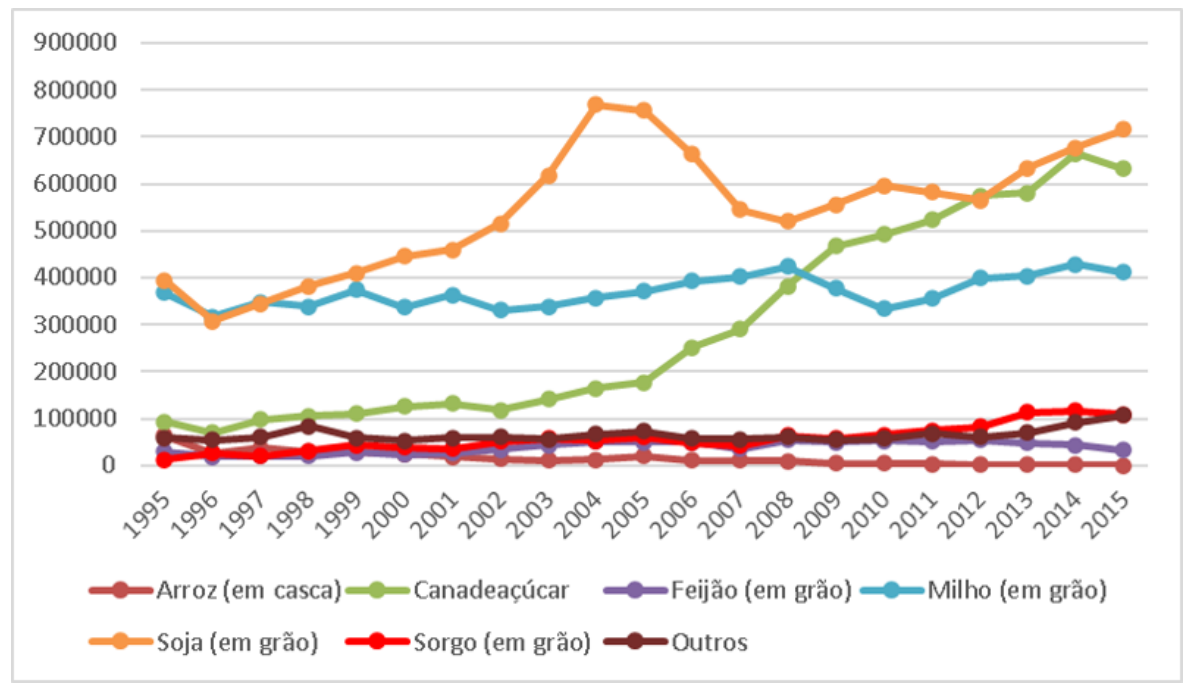

Fonte: IBGE - PAM, 2020.

Mesmo com a expressiva produção de outras commodities no Triângulo Mineiro, especialmente grãos, alguns municípios com pequeno efetivo populacional e economia pouco diversificada conheceram processos significativos de especialização territorial agrícola nas situações marcadas pela rápida expansão da cana-de-açúcar, que logo se tornou o principal cultivo realizado nos seus espaços territoriais. Quando a especialização da produção no campo somou-se à inserção de modernos objetos técnicos muito intensos em capital, como as usinas sucroenergéticas, as sedes dos municípios especializados, que denominamos como "cidades da cana" (Pereira, 2014), em verdadeira condição de realização da produção agrícola/agroindustrial (Lencioni, 1985), tornaram-se espaços muito dependentes e vulneráveis às lógicas do setor.

Assim, o fenômeno das cidades da cana, no contexto do Triângulo Mineiro, emerge a partir das seguintes características (Pereira, 2014): (i) são sedes de municípios pouco populosos e que possuem uma ou mais usinas sucroenergéticas instaladas; (ii) na maioria dos casos há destacado predomínio da cultura de cana quando comparada ao conjunto dos demais cultivos agrícolas (tanto os temporários quanto os permanentes); (iii) tais núcleos 
possuem economia predominantemente pautada na atividade agropecuária (setor primário) ou agroindustrial (secundário), resultantes das atividades sucroenergéticas ${ }^{1}$

A existência destas cidades, em tal contexto, é uma das expressões de dependência do território à lógica do agronegócio globalizado (Elias, 2006), tendo em vista que a especialização territorial produtiva sucroenergética, por um conjunto de características intrínsecas ao setor, acaba por produzir certo engessamento do território (Castillo, 2015), impedindo outras possibilidades de trabalho e a manutenção de tipos de produção agrícola. Com poucas alternativas para a ampliação ou diversificação do trabalho e economia local, estes núcleos tornam-se reféns e muito vulneráveis às práticas do agronegócio e às dinâmicas do setor sucroenergético.

\section{Especialização e vulnerabilidade territorial: Canápolis e Capinópolis (MG)}

Cabe-nos aqui demonstrar o que cremos ser expressões máximas da vulnerabilidade territorial resultante da especialização oriunda das atividades do setor avaliando os casos dos municípios de Canápolis e Capinópolis, visto que ambos enfrentaram o encerramento das atividades do setor em 2013, a partir da falência do Grupo João Lyra, controlador de duas unidades sucroenergéticas - a usina Laginha/Triálcool em Canápolis (desde o ano de 1988) e a usina Vale do Paranaíba em Capinópolis (controlada pelo Grupo desde 2001). Assim, propomos recuperar o processo de especialização alcançado nestes municípios e avaliar as consequências do fechamento das usinas.

O Grupo João Lyra, tradicional grupo alagoano que atuou no setor sucroenergético por várias décadas no Nordeste do país e, a partir dos anos 1980, estabeleceu-se também no Triângulo Mineiro (três usinas em Alagoas e duas em Minas Gerais) em função do alto preço e baixa qualidade das terras em Alagoas. Assim, grandes áreas em geral ocupadas pela pecuária revelaram-se muito propícias à cultura da cana-de-açúcar em Minas Gerais, também pelas boas condições edafoclimáticas. Do mesmo modo, outros grupos oriundos do Nordeste se instalam no Triângulo Mineiro, como é o caso do Grupo Carlos Lyra (irmão de João Lyra e detentor das usinas Caeté) e do Grupo Tércio Wanderley (usinas Coruripe).

Em Canápolis, a atividade sucroenergética foi inserida a partir de 1982 quando, sob os incentivos do Proálcool, se instalou a usina Triálcool, a partir de um conjunto de esforços da administração pública local (inclusive com doação de área pela prefeitura municipal) e de empresários locais que investiram na atividade. Sem obter o lucro almejado, o empreendimento foi adquirido pelo Grupo João Lyra em 1988, aumentando consideravelmente a produção da unidade, especialmente açúcar, ao longo da década de 1990. Visualizando um cenário favorável ao crescimento do setor, o Grupo João Lyra adquiriu em 2001 uma usina no município vizinho de Capinópolis (originalmente resultado de investimentos de empresários paulistas na década de 1980). Em Capinópolis, as atividades de formação

1 Tal situação no Triângulo Mineiro pode ser reconhecida nas cidades de Araporã, Campo Florido, Canápolis, Capinópolis, Carneirinho, Conceição das Alagoas, Conquista, Delta, Itapagipe, Iturama, Limeira do Oeste, Pirajuba, Santa Vitória e Tupaciguara. 
das lavouras de cana se iniciam no final da década de 1980, sendo a primeira safra moída em 1990/1991, na usina Vale do Paranaíba, incorporada pelo Grupo João Lyra (Fig. 4).

Figura 4. Usina Vale do Paranaíba (Grupo João Lyra), no município de Capinópolis, MG.

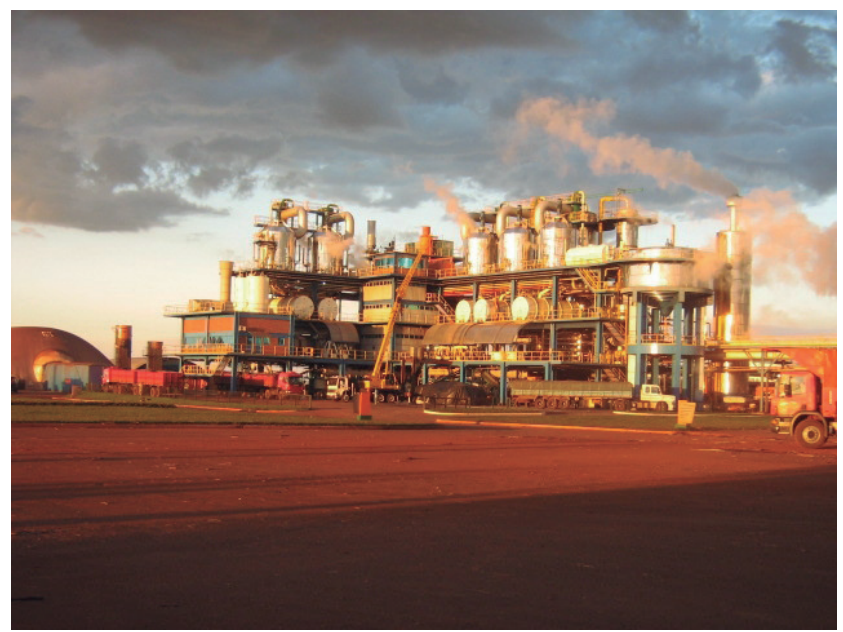

Foto: Sindicato dos Trabalhadores Rurais de Capinópolis, s.d.

A produção controlada pelo Grupo João Lyra em território mineiro era realizada tanto em terras próprias quanto em áreas arrendadas, o que com o passar do tempo, e o aumento da produção, acabou por estimular a expansão da cultura, aumentado o grau de especialização dos municípios. Este fenômeno pode ser observado pela evolução da área destinada à cana, que cresce de modo significativo, alcançando seu ápice no final dos anos 2000 (Tab. 1). Tal especialização é maior no município de Canápolis, onde mais de um terço da área total do município era coberto pela cana-de-açúcar entre os anos de 2007 e 2009, e mais de $80 \%$ da área destinada às lavouras temporárias também era voltada ao cultivo da cana (Tabs. 2 e 3).

Tabela 1. Área destinada à cultura da cana-de-açúcar - municípios selecionados (hectares)

\begin{tabular}{c|c|c|c|c|c|c|c|c}
\hline & $\mathbf{2 0 0 1}$ & $\mathbf{2 0 0 3}$ & $\mathbf{2 0 0 5}$ & $\mathbf{2 0 0 7}$ & $\mathbf{2 0 0 9}$ & $\mathbf{2 0 1 1}$ & $\mathbf{2 0 1 3}$ & $\mathbf{2 0 1 5}$ \\
\hline Canápolis & 25000 & 20000 & 22000 & 30700 & 31000 & 27000 & 23200 & 10000 \\
\hline Capinópolis & - & 2043 & 5150 & 8372 & 8000 & 8856 & 8500 & 2265 \\
\hline
\end{tabular}

Fonte: IBGE-PAM, 2020.

Tabela 2. Porcentagem (\%) de área destinada à cultura da cana sobre a área de lavouras temporárias do município - municípios selecionados.

\begin{tabular}{c|c|c|c|c|c|c|c|c}
\hline & $\mathbf{2 0 0 1}$ & $\mathbf{2 0 0 3}$ & $\mathbf{2 0 0 5}$ & $\mathbf{2 0 0 7}$ & $\mathbf{2 0 0 9}$ & $\mathbf{2 0 1 1}$ & $\mathbf{2 0 1 3}$ & $\mathbf{2 0 1 5}$ \\
\hline Canápolis & 71,7 & 71,0 & 62,8 & 80,3 & 83,7 & 81,7 & 66,0 & 33,0 \\
\hline Capinópolis & - & 6,0 & 14,0 & 19,7 & 18,5 & 18,2 & 15,1 & 4,2 \\
\hline
\end{tabular}

Fonte: IBGE-PAM, 2020. 
Tabela 3. Porcentagem (\%) de área destinada à cultura da cana sobre a área total do município municípios selecionados.

\begin{tabular}{c|c|c|c|c|c|c|c|c}
\hline & $\mathbf{2 0 0 1}$ & $\mathbf{2 0 0 3}$ & $\mathbf{2 0 0 5}$ & $\mathbf{2 0 0 7}$ & $\mathbf{2 0 0 9}$ & $\mathbf{2 0 1 1}$ & $\mathbf{2 0 1 3}$ & $\mathbf{2 0 1 5}$ \\
\hline Canápolis & 29,8 & 23,8 & 26,2 & 36,6 & 36,9 & 32,2 & 27,6 & 11,9 \\
\hline Capinópolis & - & 3,3 & 8,3 & 13,5 & 12,9 & 14,3 & 13,7 & 3,6 \\
\hline
\end{tabular}

Fonte: IBGE-PAM, 2020.

Os dados revelam o quanto a produção diminui, a partir do ano de 2011, quando o Grupo João Lyra entra em dificuldades financeiras e, conforme relatos recolhidos em trabalho de campo, diminui progressivamente os investimentos nos cultivos, até em 2013 paralisar definitivamente as atividades nas duas usinas, acarretando a partir de então substancial decréscimo da área cultivada. Com a falência do Grupo decretada em 2013, numerosos proprietários das terras arrendadas à usina deixaram de receber e também tiveram acesso negado às propriedades em função de impasses judiciais, os quais, em alguns casos, impediram por anos a retomada do cultivo.

Ainda que não figurem entre os maiores produtores de cana-de-açúcar da região (vide Fig. 2), a renda do trabalho praticado no campo em ambos os municípios foi, até o final da primeira década dos anos 2000, substancialmente oriunda do cultivo da cana. A cana-de-açúcar era a cultura de maior valor em Canápolis, do início dos anos 2000 até o ano de 2011, enquanto que em Capinópolis, no mesmo ano de 2011, cerca de $40 \%$ do valor total da produção agrícola era também oriunda da cana-de-açúcar (Figs. 5 e 6).

Figura 5. Valor da produção agrícola total e da produção de cana-de-açúcar, Canápolis, MG (2000-2015).

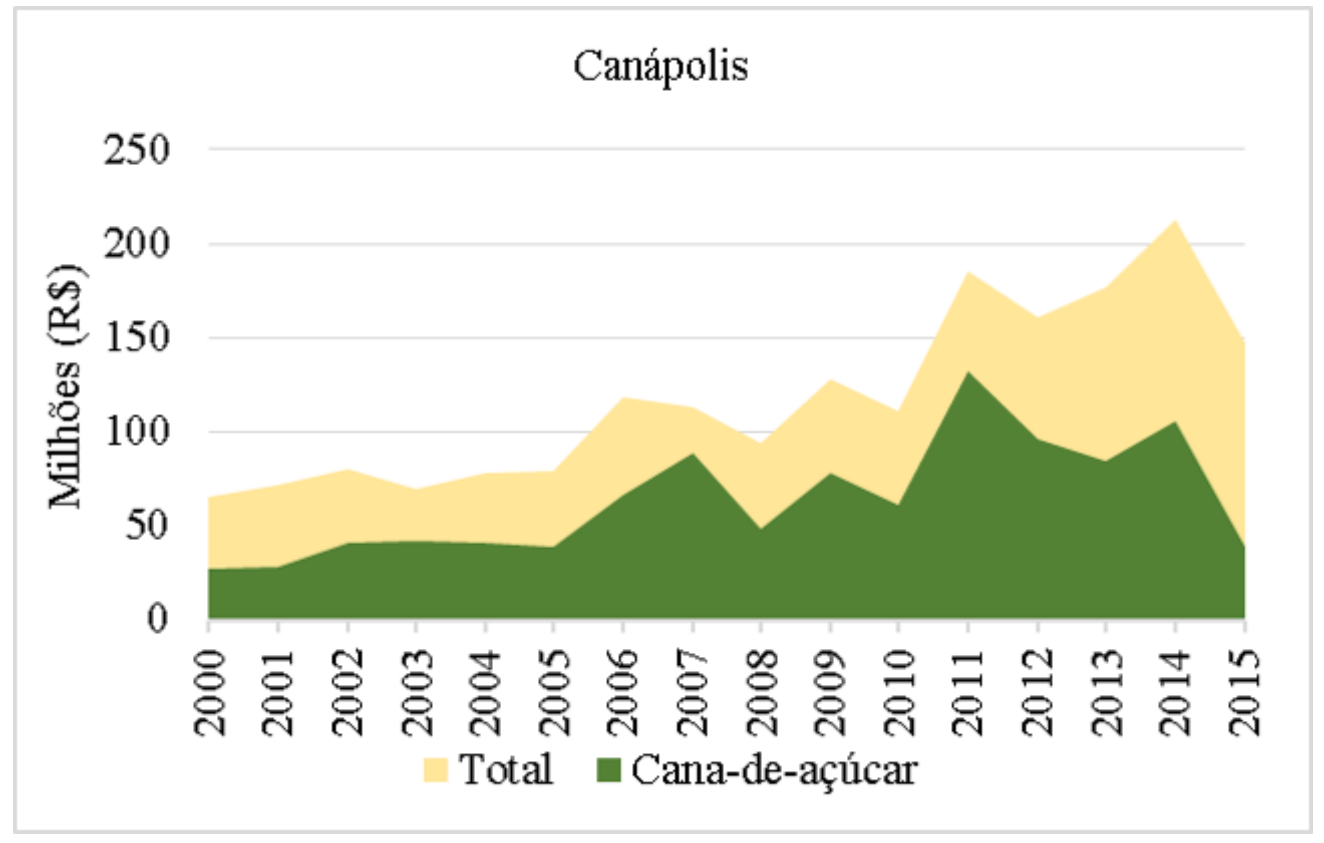

Fonte: IBGE-PAM, 2020. 
Figura 6. Valor total da produção agrícola total e da produção de cana-de-açúcar, Capinópolis, MG (2000-2015).

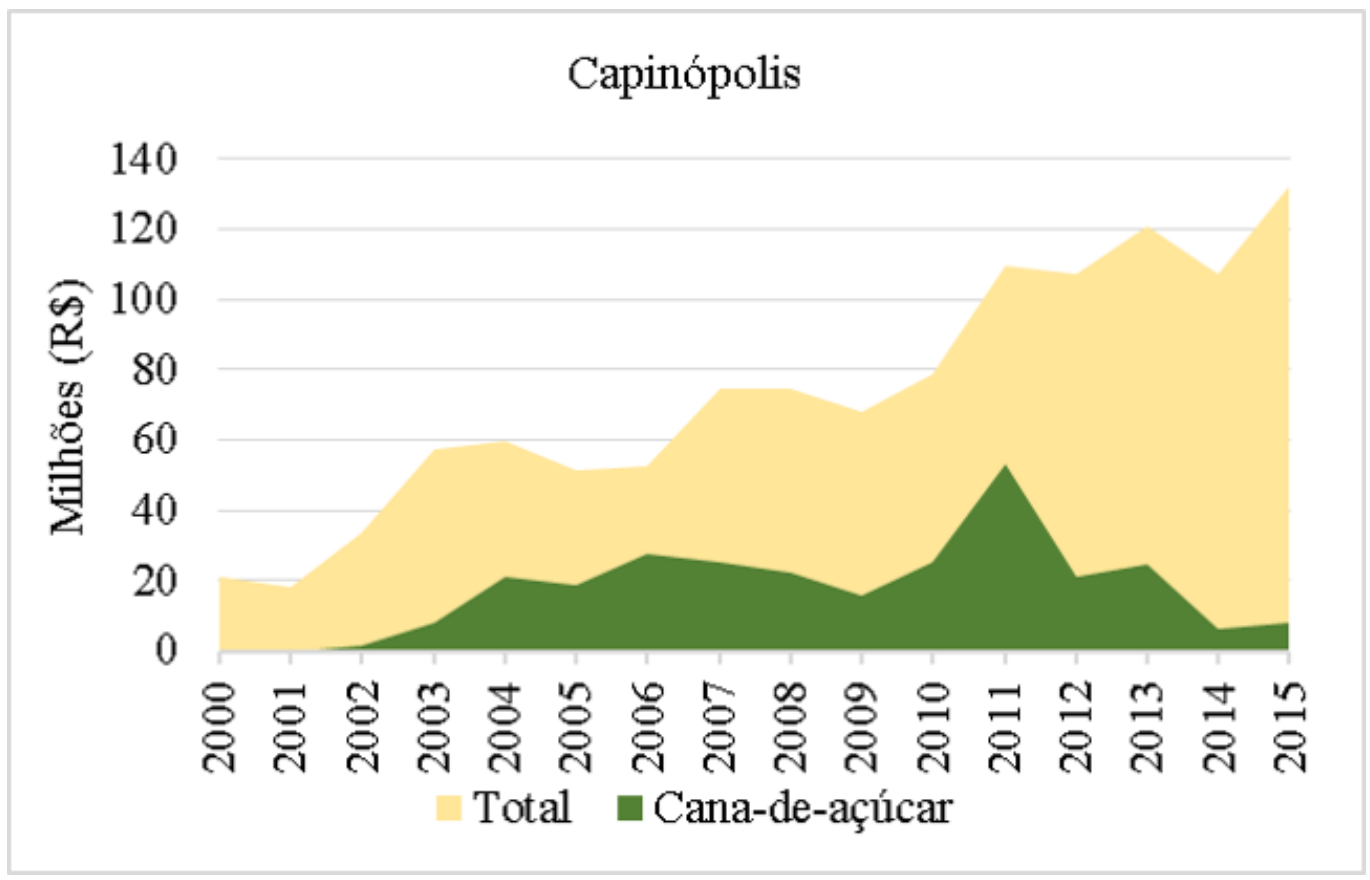

Fonte: IBGE-PAM, 2020.

Tanto em Alagoas como em Minas Gerais, o Grupo praticou o modelo tradicional de produção, com esquemas verticalizados (Reydon \& Postal, 2016), controlando ao mesmo tempo a produção agrícola (terras próprias) e industrial, ainda que, posteriormente, também tenha arrendado terras, especialmente a partir dos anos 2000 no Triângulo Mineiro. O emprego da queima e do corte manual foi mantido pelo Grupo até o encerramento das atividades, empregando grande número de trabalhadores rurais durante a safra, mesmo enquanto outros grupos já praticavam ou ensaiavam a substituição quase completa do corte mecanizado.

Como boa parte da cana processada na usina Vale do Paranaíba em Capinópolis era procedente de municípios vizinhos, esta circunstância amenizou os efeitos da crise e encerramento das atividades do setor no município e assim pode, de forma mais rápida, expandir o valor da produção agrícola com o cultivo de grãos já a partir de 2014, enquanto que em Canápolis (onde o Grupo João Lyra possuía a maior parte de suas terras próprias no Triângulo Mineiro), o valor da produção agrícola apresentou queda de quase 30\% no mesmo período.

Ambos os municípios possuem pequeno efetivo populacional. No último censo demográfico de 2010, Canápolis apresentava 11.365 habitantes, sendo 15.290 em Capinópolis. As usinas eram os maiores empregadores nos municípios e, seja no que se refere ao emprego urbano/industrial, seja no que se refere ao emprego no campo, o setor sucroenergético fundamentalmente movia a economia dos municípios. A Tabela 4 , relativa aos dados de emprego formal divulgados pelo Ministério do Trabalho e Emprego (RAIS/Caged), indicavam, no ano de 2012, 491 empregos na atividade industrial do setor em Canápolis, 
enquanto mais de 700 trabalhadores dos municípios desenvolviam atividades rurais voltadas especificamente ao trabalho na cultura da cana (Brasil, 2018). Até o ano de 2013 todo o trabalho de corte era manual e desempenhado por trabalhadores rurais (conforme informação obtida no Sindicato dos Trabalhadores Rurais de Canápolis), o que implicava, comumente, no emprego de mão de obra local e sobretudo de cortadores oriundos de outras regiões do país, notadamente do Nordeste. Somando os empregos gerados na indústria do setor aos trabalhadores rurais empregados no corte (total de mais de 1.200 postos de trabalho), e tendo em vista que os empregos formais no município totalizavam, no mesmo ano de 2012, cerca de três mil postos de trabalho, podemos afirmar que um terço da população com emprego formal foi diretamente afetada com o fechamento da usina no ano de 2013. Em Capinópolis, existiam pouco mais de 1.100 vínculos na indústria do setor sucroenergético, sendo a usina o maior empregador. A avaliação do trabalho rural em Capinópolis é difícil de ser realizada, tendo em vista que os trabalhadores rurais (corte e manejo da cana) eram empregados a partir de contratações realizadas em outros municípios da região (Canápolis, Monte Alegre de Minas e Ituiutaba, conforme relatos em campo). Como não havia outra usina em funcionamento no município, os efeitos sobre o trabalho local foram extremamente significativos (cerca de 1.000 postos de trabalho perdidos em 2013, num universo de pouco mais de 3.500 trabalhadores formais no município) (Brasil, 2018).

Nos dois casos, encontramos de forma emblemática a situação das chamadas "cidades da cana" (Pereira, 2014), onde os nexos com o setor, para além da produção agrícola propriamente dita, produzem dependência em todo o trabalho cotidiano realizado nos municípios.

Tabela 4 - Número de trabalhadores empregados segundo Classe CNAE 2.0.

\begin{tabular}{|c|c|c|c|c|}
\hline Ano & Município & Cultivo de cana-de-açúcar & Fabricação de açúcar em bruto & Fabricação de álcool \\
\hline \multirow{2}{*}{2006} & Canápolis & 29 & 1571 & 0 \\
\hline & Capinópolis & 2 & 1184 & 0 \\
\hline \multirow{2}{*}{2007} & Canápolis & 39 & 1332 & 0 \\
\hline & Capinópolis & 1 & 1038 & 0 \\
\hline \multirow{2}{*}{2008} & Canápolis & 46 & 1590 & 19 \\
\hline & Capinópolis & 1 & 1621 & 0 \\
\hline \multirow{2}{*}{2009} & Canápolis & 1249 & 448 & 19 \\
\hline & Capinópolis & 1 & 1310 & 0 \\
\hline \multirow{2}{*}{2010} & Canápolis & 1419 & 465 & 23 \\
\hline & Capinópolis & 1 & 1220 & 0 \\
\hline \multirow{2}{*}{2011} & Canápolis & 1076 & 482 & 27 \\
\hline & Capinópolis & 0 & 1329 & 0 \\
\hline \multirow{2}{*}{2012} & Canápolis & 724 & 491 & 32 \\
\hline & Capinópolis & 2 & 1113 & 0 \\
\hline \multirow{2}{*}{2013} & Canápolis & 838 & 453 & 36 \\
\hline & Capinópolis & 2 & 1109 & 0 \\
\hline \multirow{2}{*}{2014} & Canápolis & 155 & 169 & 31 \\
\hline & Capinópolis & 0 & 191 & 0 \\
\hline
\end{tabular}


conclusão

\begin{tabular}{c|c|c|c|c}
\hline \multirow{2}{*}{ Ano } & Município & Cultivo de cana-de-açúcar & Fabricação de açúcar em bruto & Fabricação de álcool \\
\hline \multirow{2}{*}{2015} & Canápolis & 68 & 225 & 36 \\
\cline { 2 - 5 } & Capinópolis & 1 & 163 & 0 \\
\hline \multirow{2}{*}{2016} & Canápolis & 81 & 11 & 36 \\
\cline { 2 - 5 } & Capinópolis & 0 & 10 & 0 \\
\hline
\end{tabular}

Fonte: MTE - RAIS (Brasil, 2018).

\section{Os efeitos do encerramento das atividades}

Enfrentando dificuldades financeiras desde meados dos anos 2000, o Grupo João Lyra entrou em processo de recuperação judicial em 2008 e, desde então travou acirradas negociações com seus credores, o que, no ano seguinte, deu origem a um acordo entre as partes com a definição de um plano de recuperação do Grupo. Em termos gerais, o plano de recuperação judicial previa o pagamento à devedores em onze anos. No entanto, e sem honrar os compromissos assumidos, o Grupo teve a falência decretada em 2013. O Grupo João Lyra possuía pouco mais de 19 mil ha de terras próprias e arrendava outros 25 mil ha no município de Canápolis. Ainda conforme informações da prefeitura (2016), boa parte dos proprietários não havia recebido a remuneração prevista nos contratos de arrendamento, e, deste modo, não tiveram condições de reformar as áreas para novas atividades.

A derrocada do Grupo, muito centrado na figura de João Lyra (que já fora considerado o parlamentar mais rico do país), aconteceu pelo acúmulo de diversos fatores, como a prática denunciada de trabalho análogo ao escravo em suas terras, crimes de corrupção, inclusive de assassinato, endividamentos de campanha, etc. (Torres, 2012). Desde 2013 diversas manobras jurídicas fizeram com que as usinas do Grupo não fossem vendidas, adiando cumprimento de contratos e remuneração de conjunto numeroso de trabalhadores e credores. Segundo o Sindicato dos Trabalhadores Rurais de Capinópolis, o maior problema referente ao Grupo João Lyra adveio de sua força e poder político para arrolar dívidas por diversos anos. De certo modo, o Grupo obteve um aditamento da justiça e do poder público local, mas não cumpriu acordos estabelecidos. Em Capinópolis, o Grupo João Lyra, foi autuado no ano de 2010 por manter 207 trabalhadores em condições análogas à de escravidão (Pyl, 2010). Em trabalho de campo ${ }^{2}$, nos foi relatado pelo Sindicato dos Trabalhadores Rurais práticas típicas de superexploração do trabalho, como a oferta de prêmios (motocicletas, por exemplo) aos trabalhadores com maior rendimento durante a safra, resultando em uso de drogas estimulantes e diversos problemas físicos aos cortadores.

A partir de então, inicia-se um lento processo para efetivar a venda da massa falida, visando restituição de credores e funcionários, que se concretizou a partir de leilão público no final do ano de 2017. Devendo a trabalhadores, arrendatários e mesmo às prefeituras municipais, os efeitos do fechamento das usinas são significativos nos dois municípios. Cerca de $70 \%$ dos cortadores eram habitantes ou migrantes que residiam em Capinópolis durante 
a safra. Ainda segundo informações da prefeitura, tal situação permitia mensalmente com que cerca de $\mathrm{R} \$ 2,5$ milhões (total da folha de pagamento) circulassem na cidade durante a safra, movimentando a economia local. O setor de comércio e serviços sofreu, deste modo, significativa queda de atividades e, assim, em 2014, o município também conheceu uma redução de $40 \%$ na arrecadação de ICMS. O setor imobiliário foi afetado de forma direta, tendo em vista que famílias deixavam de saldar compromissos com aluguel, bem como imóveis alugados para trabalhadores migrantes tornavam-se ociosos.

Em entrevista junto à prefeitura ${ }^{3}$ de Canápolis, foi relatado que a usina era a mais importante geradora de emprego no município e responsável por mais da metade do Valor Adicionado Fiscal (VAF) do município. Sua situação torna-se precária com o fechamento da usina, pois a queda na arrecadação de impostos implicou em dificuldades em manter os serviços públicos, gerando cortes no orçamento que atingiram áreas como educação e saúde. Para além das dívidas junto aos trabalhadores da usina e aos que arrendavam terras, o Grupo João Lyra devia cerca de $\mathrm{R} \$ 11$ milhões à prefeitura de Canápolis (resultantes de taxas e ISS não recolhidas), montante este que fora habilitado na massa falida do Grupo.

Se de algum modo o efeito de especialização territorial e a elaboração da condição de vulnerabilidade resultaram das ações da própria empresa, é necessário pensar na quanto tal opção também foi defendida e encampada pelos municípios. Segundo informações da própria prefeitura, o auge das atividades da usina em Canápolis ocorreu entre 1995 e 2005. Este também é o período em que a cidade conheceu grande afluxo de migrantes para o corte, inclusive com importante quantia de migrantes nordestinos fixando-se definitivamente no município, típica condição das cidades da cana (Pereira, 2016). O volume de nascidos no Nordeste com residência em Canápolis dobrou de tamanho entre 2000 e 2010, para 2.098 habitantes, o que correspondia a 18\% da população total (IBGE, 2010),

Segundo a Secretaria de Ação Social do Município, logo após o encerramento das atividades em Canápolis houve imensa demanda de passagens para retorno ao Nordeste, além da busca por auxílio em cestas básicas, auxílio-gás, água e energia elétrica ${ }^{4}$. A queda na atividade comercial resultou em mais desemprego e dificuldades em saldar as prestações de casas adquiridas em programas de habitação, como o Minha Casa, Minha Vida, por exemplo. A ação de programas governamentais de auxílio à população de baixa renda tornou-se fundamental para a manutenção de famílias, ainda que os recursos fossem. Segundo a Caixa Econômica Federal (CEF, 2015), em 2014, 448 famílias recebiam recursos do Programa Bolsa Família, o que constituía cerca de 13\% das famílias do município.

Ao mesmo tempo em que a especialização produtiva gerou novas condições e características à cidade, como a expansão da monocultura e certa valorização das terras em Canápolis, outras atividades foram, desde os anos 1980, tornadas residuais pela própria expansão e centralidade tomada pela cana, ainda que figurem agora como alternativas de emprego e geração de renda no município. Além da tradicional pecuária bovina, continuam

3 Entrevista realizada com o secretário municipal de governo de Canápolis, em 06 de agosto de 2015.

4 Segundo dados da Secretaria Municipal de Ação Social (agosto/2015), a prefeitura de Canápolis tem restrições em garantir tais auxílios. Outras ações de amparo social são realizadas em parceria com ONGs e igrejas, e dependem fundamentalmente de recursos não fixos. 
uma destilaria de pequeno porte, produzindo principalmente aguardente, e três pequenos empreendimentos que processam doces e geleias de abacaxi, uma cultura realizada há décadas no município.

Marcada igualmente pela presença de uma mão de obra migrante, durante mais de dez anos a cidade de Capinópolis verificou crescimento no comércio e serviços locais, sofrendo assim sérias consequências com a desativação da usina. As alternativas imediatas de realocação para os trabalhadores, ainda conforme o sindicato, se restringiam a busca por oportunidades em outras usinas do setor (em Santa Vitória-MG ou na também vizinha Cachoeira Dourada de Goiás-GO), além da construção civil (Programa MCMV). O Programa Bolsa Família acabou garantindo alguma renda para parte considerável do município. Em 2014 foram atendidas 989 famílias, cerca de 20\% das famílias do município (CEF, 2015).

Segundo a Prefeitura Municipal, o VAF do município caiu cerca de 20\%, além de dívidas municipais não honradas pelo Grupo João Lyra que alcançavam cerca de R\$ 5 milhões. Foram relatados problemas gerados no comércio local, além do fechamento ou retirada do município de prestadoras de serviços ligadas ao setor, como oficinas mecânicas, empresas de transporte, etc.

Mesmo assim, o grau de dependência das atividades sucroenergéticas em Capinópolis é de certo modo menor do que em Canápolis, devido a existência de outras atividades que foram capazes de absorver parte da mão de obra dispensada e evitar maiores perdas na arrecadação de impostos. O cultivo de grãos é em parte processado no próprio município, com uma unidade da Dow Agrosciences e também uma unidade de recepção de grãos da Algar Agro. Desde 2014 há escritório da SJC Bioenergia (São João-Cargill Bioenergia) recrutando mão de obra para os cultivos de cana realizados no município, aproveitando a ocasião de encerramento das atividades da usina para ampliar a área de produção de cana-de-açúcar no território mineiro ${ }^{5}$.

Como podemos constatar, a situação de vulnerabilidade nos núcleos urbanos é imediatamente sentida nos municípios que passam por processos acentuados de especialização. A economia, o emprego e a geração de renda nas cidades da cana, para além da atividade agroindustrial, resumem-se a poucas atividades de um setor terciário em sua maior parte composto por um circuito inferior da economia urbana (Santos, 2004). São pequenos estabelecimentos de comércio e serviços que abastecem a população com bens essenciais, sendo a aquisição de bens e serviços especializados buscados muitas vezes em cidades maiores, como Ituiutaba ou Uberlândia.

O próprio comércio local era, conforme nos fora relatado em campo, muito ritmado pelo trabalho realizado nas usinas, ganhando maior movimento em período de safra. Não oferecendo recursos capazes de viabilizar facilmente outro tipo de atividade, a economia

5 Segundo informações de campo (agosto de 2015), o Grupo SJC Bioenergia, visando ampliar sua área de arrendamento e suprir as demandas de uma usina instalada em Cachoeira Dourada de Goiás (GO), conta com cerca de 7 mil hectares arrendados para plantio de cana em Capinópolis e outros municípios da região, com contratos iniciados desde o ano de 2010 (colhendo cerca de 250 mil toneladas em Minas Gerais em 2015). Investiu, inclusive, na construção de um pequeno porto e balsa, para transpor o rio Paranaíba (divisa de Minas Gerais e Goiás), visando reduzir os custos de transporte. O Grupo SJC Bioenergia emprega cerca de 130 trabalhadores (70 deles rurais) contratados em Capinópolis, e assim figura como uma opção aos proprietários de terra que antes arrendavam ao Grupo João Lyra. 
urbana é, assim, atrofiada e muito dependente do dinheiro que circula em função do setor sucroenergético. A arrecadação municipal é incapaz de solver as demandas sociais e os problemas ambientais normalmente oriundos da atividade, tornando as cidades reféns de sua especialização produtiva e imersas numa situação de instabilidade territorial (Silveira, 2002), própria das oscilações de um trabalho regido por interesses distantes.

\section{Alternativas encontradas pelos municípios: para pensar o caráter vulnerável da es- pecialização territorial}

Quais ações poderiam figurar como possíveis alternativas à situação encontrada nestes municípios? O que poderia recuperar semelhante quantidade de empregos e novo dinamismo aos serviços e à economia urbana? Por quais meios as perdas da arrecadação municipal e a manutenção dos serviços públicos essenciais poderiam ser recuperados?

Em ambos os municípios, tanto nas prefeituras, sindicatos de produtores e de trabalhadores rurais, ou mesmo ao ouvir pelas ruas os cidadãos comuns, desde o encerramento das atividades do Grupo João Lyra até os anos de 2015 e 2016, quando realizamos incursões de campo, era evidente a expectativa de que as usinas retomassem a produção para que, enfim, houvesse um possível reforço das atividades econômicas de modo geral.

Aparentemente não restam esperanças de outras atividades, e o futuro almejado sempre remete às práticas costumeiras de um passado recente, ancorado nas práticas do setor sucroenergético. Com a decretação da falência do Grupo João Lyra, aparecem propostas de compra das infraestruturas produtivas, tanto em Canápolis quanto em Capinópolis (com interesse de grupos que atuam na região, como Companhia Mineira de Açúcar e Álcool e BP Energy), assim como propostas mais flexíveis, como a de arrendamento das usinas pelo Grupo SJC Energia 6 .

Avaliando a situação de dependência e vulnerabilidade dos dois municípios, poderíamos crer, à primeira vista, que novas políticas poderiam ser implantadas, de modo a tornar o campo e as cidades menos dependentes do setor sucroenergético. No entanto, e a partir de constatações obtidas em campo junto à administração municipal de ambos os municípios, verificamos um conjunto de esforços para viabilizar a retomada das atividades industriais do setor, visando, desta forma, recuperar o número de empregos e reestabelecer a arrecadação municipal nos moldes anteriores.

Passados quatro anos da decretação de falência do Grupo João Lyra, as instalações localizadas em Canápolis e Capinópolis foram leiloadas no ano de 2017, depois de diversos impasses jurídicos que por várias vezes adiaram a venda da massa falida em favor de credores. A usina Triálcool, localizada em Canápolis, inicialmente avaliada em $\mathrm{R}$ \$ 223,04 milhões, foi adquirida em leilão por $\mathrm{R}$ \$ 133,3 milhões pela Companhia Mineira de Açúcar e Álcool (CMAA), empresa de capital aberto, gerenciado pela JFCitrus (Brasil) e IndoAgri (Indonésia), controladora de outras duas unidades no Triângulo Mineiro (em Uberaba e Limeira do Oeste). A CMAA criou a partir do patrimônio adquirido, a Canápolis Açúcar e Álcool S.A., reativando a produção de cana em terras próprias (6 mil hectares) e

6 Conforme informações recolhidas na prefeitura de Canápolis, MG. 
arrendadas, retomando o processamento em 2020 (capacidade para 1,76 milhões de ton./ ano). Por sua vez, a usina Laginha, localizada em Capinópolis, foi adquirida por meio de leilão também em 2017, e arrematada por R \$ 206,3 milhões pelo Grupo Japungu (que controla outras usinas na Paraíba e em Goiás), com previsão de retomada para o ano de 2020 do processamento de 1,7 milhões de toneladas/ano, na agora denominada CRV-Vale do Paranaíba (Laginha Agroindustrial, 2018).

Tal situação, comemorada pelos municípios, evidencia mais uma condição de engessamento do território pelo setor sucroenergético (Castillo, 2015), tendo em vista que as dificuldades e restrições para o acolhimento de novas funções e atividades produtivas permanece nos municípios mesmo quando as atividades sucroenergéticas são paralisadas ou encontram-se ociosas.

O volume de investimentos imobilizado no território, a partir de um conjunto de infraestruturas das usinas, revela, deste modo, a concretude e o peso do "território como norma" , conforme reflexão de Milton Santos (1996), em que os objetos técnicos são capazes de orientar ações, funções e comportamentos. Como tais infraestruturas resultam de um planejamento que interessa aos agentes hegemônicos, implantadas outrora por outros agentes, e controladas a partir de agora por agentes econômicos ainda mais poderosos, são as usinas que, de certo modo, passam a comandam a população e o lugar, e não o contrário. Trata-se, em última análise, de uma prática invertida de uso do território (Pereira, 2011), em que as demandas próprias da existência e do conjunto da sociedade se dão em detrimento de interesses corporativos.

\section{CONSIDERAÇÕES FINAIS}

A expansão das atividades do setor sucroenergético ocorrida no início do século no Brasil e, particularmente, no Triângulo Mineiro, exemplifica a situação de instabilidade e de vulnerabilidade do território, própria das condições de submissão do país à produção de commodities. Tal processo pode ser observado em diferentes escalas, seja a do território nacional, seja a das regiões, algumas delas tornadas competitivas e especializadas, tal como se estabelece no Triângulo Mineiro, ou, ainda, na escala dos municípios, onde a amplitude dos problemas e da vulnerabilidade territorial ganha contornos nítidos. Os casos emblemáticos de Canápolis e Capinópolis podem, assim, se repetir em municípios ${ }^{7}$ que recentemente conhecem forte orientação e prevalência do setor sucroenergético, reorientando demasiadamente as práticas produtivas e as políticas locais.

Em que pese um conjunto mais extenso de problemas relacionados ao setor, como a subordinação de produtores/fornecedores e de proprietários de terra, concentração fundiária, exploração da força de trabalho, impactos ambientais de grandes dimensões, etc, o que arriscamos denominar como cidades da cana constitui, no Triângulo Mineiro, uma situação geográfica importante para revelar a política de um uso corporativo do território pelo setor sucroenergético, também a partir de nexos urbanos. Assim, confiar o desenvolvimento da

7 Apenas em 2019 mais de vinte unidades agroindustriais sucroenergéticas entraram com pedidos de recuperação judicial. Esta era a situação de 82 unidades no país (CANAONLINE, 2020). 
região, dos municípios e de pequenas cidades às práticas do agronegócio, da forma como ele se realiza hoje, é um exercício puro de abstração (Ribeiro, 2005), praticado pelo Estado, pelas empresas e pelas classes que tiram proveito da situação estabelecida.

Não há dúvida de que tais situações de especialização territorial produtiva revelam o claro prejuízo dos lugares, em função do limitado ou mesmo nulo poder de coordenação sobre o trabalho que acolhem, e, drasticamente, a dependência extrema das atividades para a economia municipal se estabelece como um círculo vicioso. Assim, as usinas sucroenergéticas, objetos geográficos dotados de intencionalidade e "presente" cobiçado pelo poder público nas pequenas cidades, podem por vezes figurar como um verdadeiro cavalo de Tróia (Santos, 2003, p.189), legitimado entre uma população que não se dá conta dos riscos e da vulnerabilidade que as acompanham.

\section{AGRADECIMENTOS}

Agradecemos à FAPEMIG - Fundação de Amparo à Pesquisa do Estado de Minas Gerais, pelo auxílio financeiro destinado à realização da pesquisa (APQ 01797-14).

\section{REFERÊNCIAS}

Bernardes, J.A. (2013). Metamorfoses no Setor Sucroenergético: emergência de contradições. In: J.A. Bernardes, R. Arruzzo, C.A. Silva. Espaço e Energia: mudanças no paradigma sucroenergético. (pp.143-155). Rio de Janeiro: Lamparina

Borras Jr, S.M., Franco, J.F., Isakson, S.R., Levidow, L., \& Vervest, P. (2013). The rise of flex crops and commodities: implications for research. The Journal of Peasant Studies, 29(1), 93-115. Doi: https:/ / doi.org/1 0.1080/03066150.2015.1036417

Brasil. Ministério do Trabalho e Emprego. Relação Anual de Informações Sociais - RAIS 2018. Brasília: Recuperado de http://trabalho.gov.br/rais/default.asp

Camelini, J.H., \& Castillo, R. (2012). Etanol e uso corporativo do território. Mercator, 11(25), 7-19. Doi:http:/ / dx.doi.org/10.4215/RM2012.1125.0001.

Castillo, R. (2015). Dinâmicas recentes do setor sucroenergético no Brasil: competitividade regional e expansão para o bioma Cerrado. GEOgraphia, 17, 95-119.

Ano de 2019 tem recorde no pedido de usinas em recuperação judicial. (2019, outubro 31). Cana Online. Recuperado de http://www.canaonline.com.br/conteudo/ano-de-2019-tem-recorde-de-usinas-compedido-de-recuperacao-judicial.html

Caixa Econômica Federal (2018). Programa Bolsa Família. Recuperado de http://www.caixa.gov.br/ programas-sociais/bolsa-familia/Paginas/default.aspx

Delgado, G.C. (2012). Do capital financeiro na agricultura à economia do agronegócio: mudanças cíclicas em meio século (1965-2012). Porto Alegre: Ed. UFRGS.

Elias, D. (2006). Globalização e fragmentação do espaço agrícola do Brasil. Scripta Nova, 1, 59-81.

Instituto Brasileiro de Geografia e Estatística. Censo Demográfico 2010. Recuperado de https://www.ibge. gov.br/

Instituto Brasileiro de Geografia e Estatística (2020). Produção agrícola municipal (PAM). Recuperado de http://sidra.ibge.gov.br 
Laginha Agroindustrial. (2018). Laginha Agroindustrial S/A. Recuperado de https:/ /laginha.datagro.com/ Lencioni, S. (1985). Agricultura e urbanização: a intensificação do capital na agricultura e a nova relação rural urbano no Estado de São Paulo. Revista do Departamento de Geografia da USP, 4, 41-51.

Pereira, M.F.V. (2010). A inserção subordinada do Brasil na divisão internacional do trabalho: consequências territoriais e perspectivas em tempos de globalização. Sociedade $\mathcal{E}$ Natureza, 22(2), 347-355. Doi:http:// dx.doi.org/10.1590/S1982-45132010000200009

Pereira, M.F.V. (2011). Território e política: práxis invertidas e desafios da existência. Sociedade \& Natureza, 23(1), 95-104. Doi: https:/ / doi.org/10.1590/S1982-45132011000100008

Pereira, M.F.V. (2014). O setor sucroenergético no Triângulo Mineiro e as "cidades da cana". Anais do Encontro Nacional de Geografia Agrária, Natal, UFRN, 22. p. 2801-2816.

Pereira, M.F.V. (2016). A migração para o trabalho e o setor sucroenergético: situações nas "cidades da cana" no Triângulo Mineiro. Anais do Encontro Nacional de Geografia Agrária, São Cristóvão, UFS, 23.13 p.

Pyl, B. (2010, setembro 8). Usina de candidato mantém 207 em quadro de trabalho escravo. Repórter Brasil. Recuperado de https://reporterbrasil.org.br/2010/09/usina-de-candidato-mantem-207-em-quadro-detrabalho-escravo/

Ribeiro, A.C.T. (2005). Outros territórios, outros mapas. Osal, 6 (16), 263-272.

Reydon, B., \& Postal, A. M. (2016). Agronegócio sucroenergético: acesso à terra ou acesso à cana? Os diferentes modelos de negócios e seus impactos na gestão empresarial. In E.A. Bühler, M. Guibert, W.L. Oliveira (Orgs.), Agriculturas empresariais e espaços rurais na globalização: abordagens a partir da América do Sul. (cap. 9, pp. 193-215). Porto Alegre: Ed. UFRGS.

Santos, M. (1996). A natureza do espaço: Técnica e Tempo. Razão e Emoção. São Paulo: HUCITEC.

Santos, M. (2003). A totalidade do diabo: como as formas geográficas difundem o capital e mudam as estruturas sociais. In M. Santos. Economia espacial: críticas e alternativas. (2a. ed., cap. 7, pp.187-204). São Paulo: Ed. USP.

Santos, M. (2004). O espaço dividido: Os dois circuitos da economia urbana nos países subdesenvolvidos. (2a. ed.) São Paulo: Ed. USP.

Silva, L.R. (2017). O BNDES e a sustentação do setor sucroenergético no Brasil: Implicações territoriais no contexto neoliberal e de financeirização. (Mestrado em Geografia). Universidade Federal de Uberlândia - UFU, Uberlândia, MG, Brasil.

Silveira, M.L. (1999). Uma situação geográfica: do método à metodologia. Território, 6, 21-28.

Silveira, M.L. (2002). Uma globalização desnecessária, um território instável. Ciência Geográfica, 21(1), 43-46. Svampa, M. (2013). ‘Consenso de los Commodities' y lenguajes de valoración en América Latina. Nueva Sociedad, 244, 30-46.

Torres, I. (2012, dezembro 14). O caso do coronel. IstoÉ, 2630. Recuperado de https:/ / istoe.com.br/261282_ $\mathrm{O}+\mathrm{OCASO}+\mathrm{DO}+\mathrm{CORONEL} /$

Data de submissão: 09/abr./2019

Data de aceite: $23 /$ maio/2020 